\title{
Management of biliopleural fistula after transarterial chemoembolization of a liver lesion
}

\author{
Amir Shahzad Butt MD, Ghulam Mujtaba MD, Sury Anand MD, \\ Mahesh Krishnaiah MD
}

\begin{abstract}
ASButt, GMujtaba, S Anand, M Krishnaiah. Management of biliopleural fistula after transarterial chemoembolization of a liver lesion. Can J Gastroenterol 2010;24(5): 281-283.

A case of a biliopleural fistula with a biloma occurring after superselective hepatic transarterial chemoembolization ablation of a metastatic hepatic carcinoid is described. The presentation was complicated by choledocholithiasis. The biloma was successfully treated with endoscopic drainage.
\end{abstract}

Key Words: Biliopleural fistula; Biloma; TACE complications

\section{CASE PRESENTATION}

A 64-year-old Caucasian woman with a carcinoid tumour with multiple liver metastases underwent superselective hepatic transarterial chemoembolization (TACE) with adriamycin (Bedford

\section{La prise en charge d'une fistule biliopleurale après la chimioembolisation transartérielle d'une lésion hépatique}

Les auteurs décrivent un cas de fistule biliopleurale accompagnée d'un bilome après l'ablation supersélective d'un carcinoïde hépatique métastatique par chimioembolisation transartérielle hépatique. La présentation était compliquée par une cholédocholithiase. Le bilome a été traité avec succès par drainage endoscopique.

Laboratories, USA) and low compressible beads over several months. Seven days after TACE of her third lesion in segment VII (Figure 1), the patient presented to the emergency room with nausea, vomiting and a productive

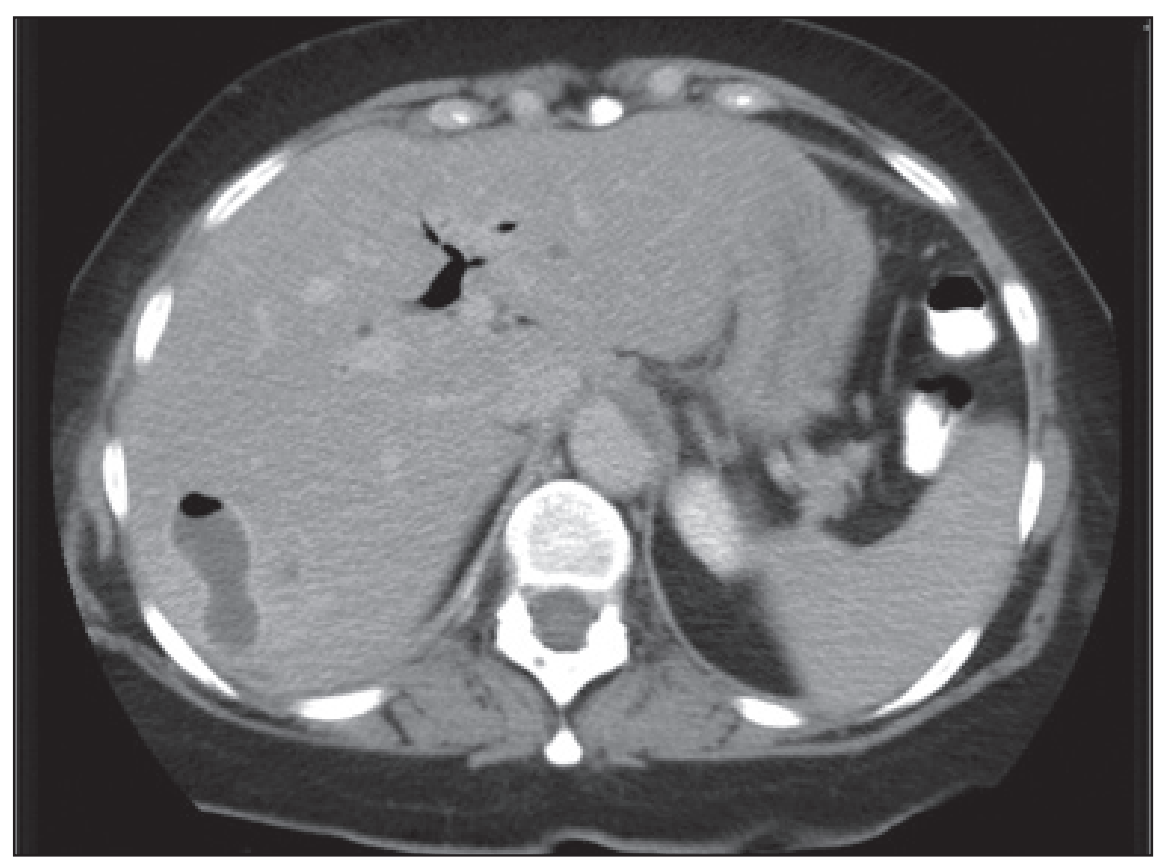

Figure 1) Computed tomography scan confirming biloma

The Brooklyn Hospital Center, Brooklyn, New York, USA

Correspondence: Dr Amir Shahzad Butt, The Brooklyn Hospital Center, 121 Dekalb Avenue Maynard Building 4th Floor, Brooklyn, New York 11201, USA. Telephone 347-756-8485, fax 718-250-6489, e-mail amir.s.butt@gmail.com

Received for publication July 17, 2009. Accepted July 19, 2009 


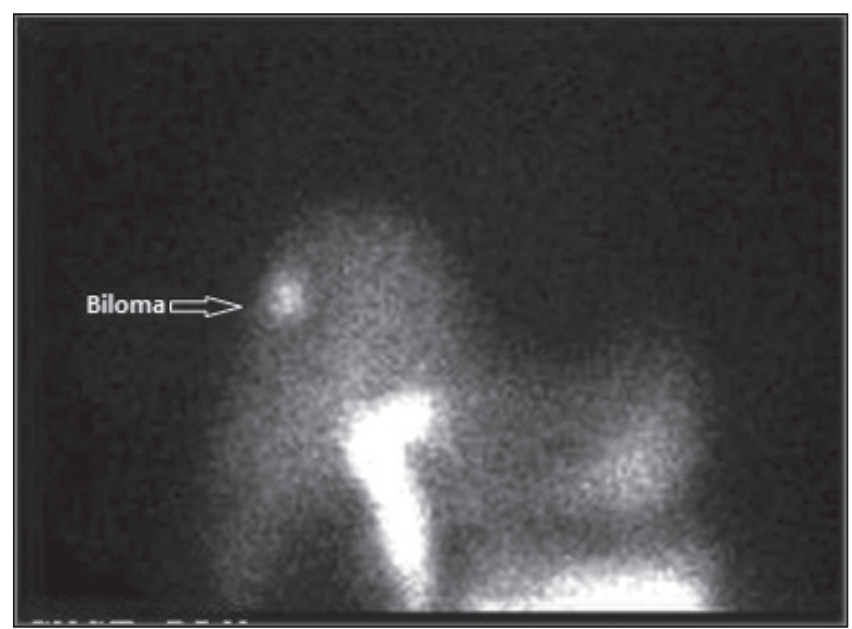

Figure 2) Hepatobiliary scan confirming biloma

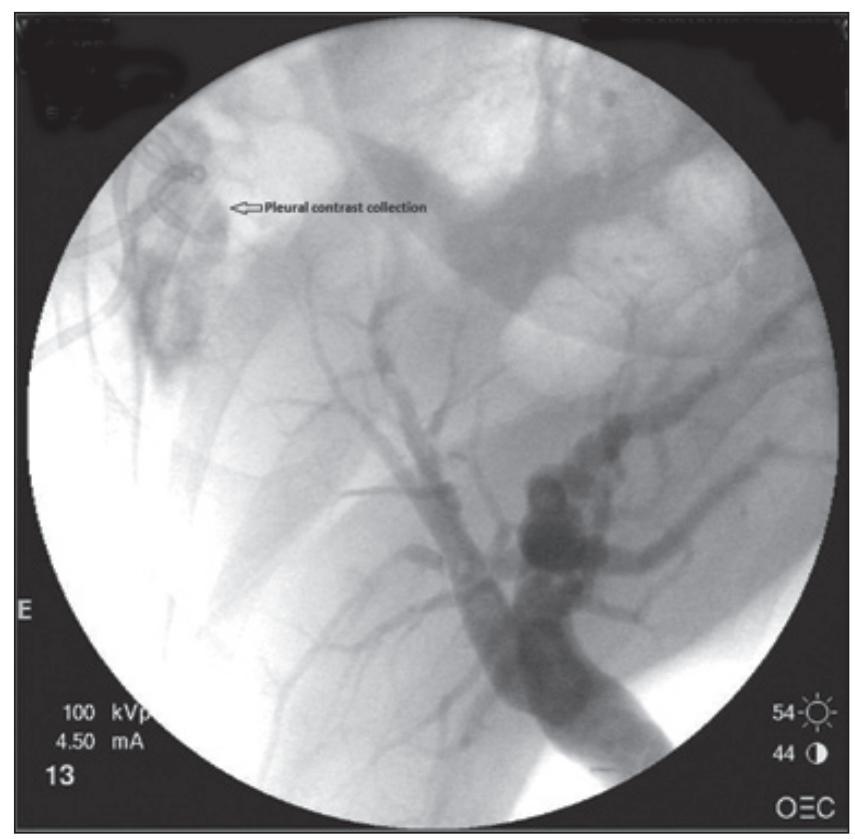

Figure 3) Endoscopic retrograde cholangiopancreatography revealing a biliopleural fistula, with contrast collecting into the pleural cavity in the region of the chest tube

cough. On examination, her breath sounds were diminished at the right lung base, with tenderness to palpation in the right upper quadrant. A chest x-ray revealed a right-sided pleural effusion. An abdominal computed tomography scan showed the pleural effusion, a right subdiaphragmatic fluid collection and a single filling defect within the common bile duct. A hepatobiliary scan confirmed a collection of bile in the subdiaphragmatic area (Figure 2). An evacuative thoracentesis fluid analysis revealed the presence of bile, confirming a biliopleural fistula (BPF). Subsequently, a chest tube was placed.

After informed consent was obtained, endoscopic retrograde cholangiopancreatography (ERCP) was performed and revealed a $\mathrm{BPF}$, with contrast collecting into the pleural cavity in the region of the chest tube (Figure 3 ) and three concomitant filling defects noted on the cholangiogram, consistent with choledocholithiasis. The intrahepatic ducts and common

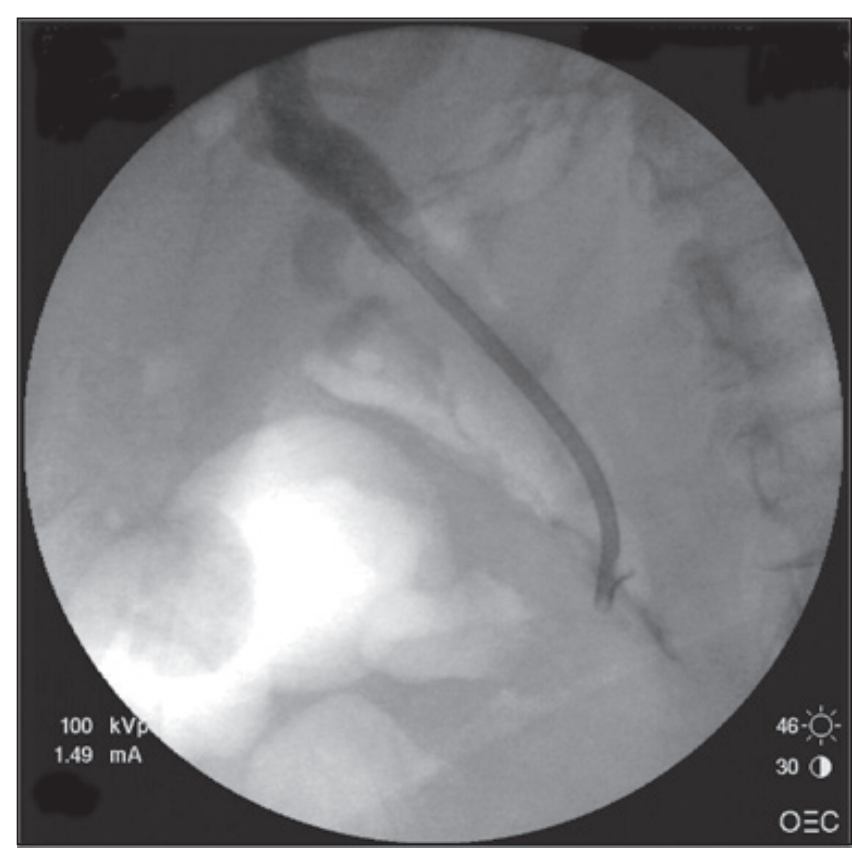

Figure 4) Endoscopic retrograde cholangiopancreatography with a $15 \mathrm{~cm}, 7 \mathrm{Fr}$ stent placement

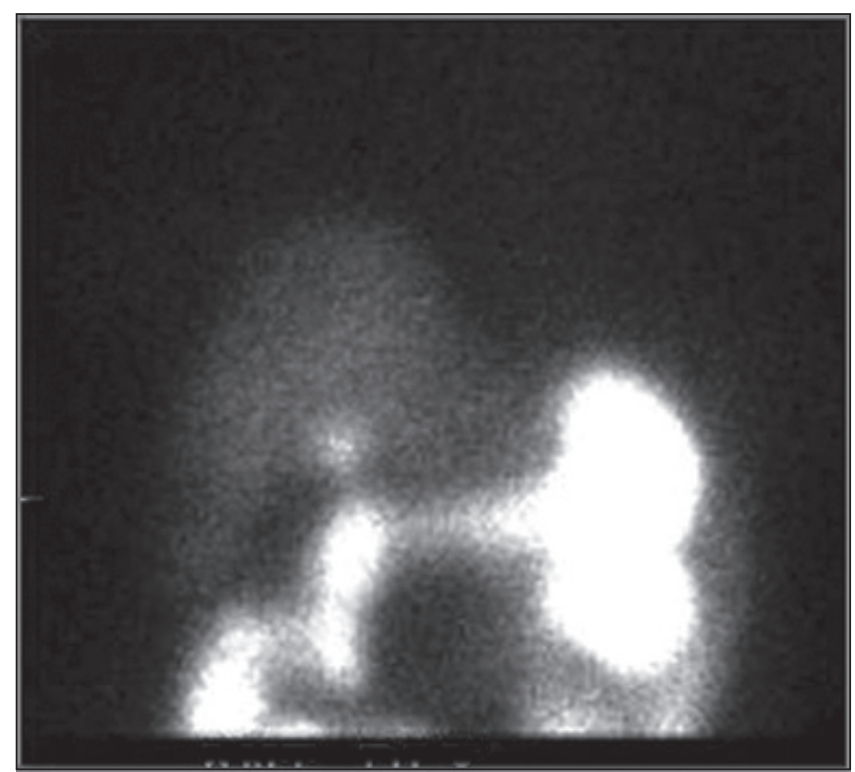

Figure 5) Hepatobiliary scan confirming resolution of the biloma

bile duct were not dilated. Biliary sphincterotomy was performed to facilitate stone extraction, which was performed with two balloon sweeps. A $15 \mathrm{~cm}, 7$ Fr plastic endoprosthesis (Boston Scientific, USA) was positioned downstream of the fistula (Figure 4), with good bile flow noted in the duodenum. Two days after ERCP, a repeat hepatobiliary scan confirmed resolution of the biloma (Figure 5), with no output noted in the chest tube drainage, which was removed that evening. The patient felt better the following morning and was discharged on day 5 after ERCP without complications.

\section{DISCUSSION}

Primary or metastatic liver lesions deemed to be unresectable or in patients who are poor surgical candidates may undergo 
TACE to improve mortality (1-3). A $\mathrm{BPF}$ is a well-described complication of radiofrequency ablation of hepatic lesions $(4,5)$. A review of the literature revealed that a $\mathrm{BPF}$ had not been previously described after TACE ablation of a metastatic hepatic lesion. After TACE, tumour cells and the adjacent normal tissue undergo necrosis secondary to ischemia and the cytotoxic properties of time-released chemotherapeutic agents (6). After tumour necrosis, a cavity is created, with bile spillage resulting in biloma formation (7). In the present case, the liver lesion was juxtaposed with the diaphragm and it was likely that the necrotic effects extended to the diaphragm, leading to bile collecting in the pleural cavity. We do not believe that the choledocholithiasis, although present, aided in the upstream flow of bile because our patient had neither obstructive symptoms nor dilated ducts on ERCP. We believe that the negative intrathoracic pressure created a favourable gradient aiding in bile collection in the pleural cavity from a lesion that was adjacent to the diaphragm. In the present case, the placement of a biliary stent likely reversed this gradient by maintaining constant patency of the common bile duct at the ampulla, and allowed drainage of the biloma and pleural collection. A further review of other cases is needed to ascertain whether a smaller dose of TACE may prevent this complication from occurring in liver lesions that juxtapose the diaphragm.

\section{REFERENCES}

1. Yamada R, Kishi K, Sato M, et al. Transcatheter arterial chemoembolization (TACE) in the treatment of unresectable liver cancer. World J Surg 1995:795-800.

2. Chung JW, Park JH, Han JK, et al. Hepatic tumors: Predisposing factors for complications of transcatheter oily chemoembolization. Radiology 1996;198:33-40.

3. Girish B, Chooi WK, Marcos SK. Trans-cather arterial chemoembolization as first-line treatment for hepatic metastases from endrocrine tumors. Eur Radiology 2003;13:136-40.

4. Wigmore SJ, Redhead DN, Thomson BN, et al. Postchemoembolisation syndrome tumour necrosis or hepatocyte injury? Br J Cancer 2003;89:1423-7.

5. Llovet JM, Bruix J. Systematic review of randomized trials for unresectable hepatocellular carcinoma: Chemoembolization improves survival. Hepatology 2003;37:429-42.

6. Bruix J, Castells A, Montanyà X, et al. Phase II study of transarterial embolization in European patients with hepatocellular carcinoma: Need for controlled trials. Hepatology 1994;20:643-50.

7. Sakamoto I, Iwanaga S, Nagaoiki K, et al. Intrahepatic biloma formation (bile duct necrosis) after transcatheter arterial chemoembolization. Am J Roentgenol 2003;181:79-87. 


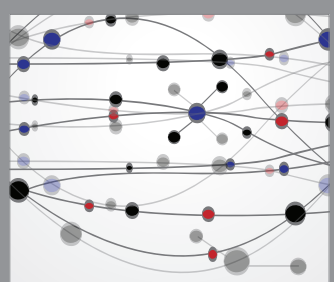

The Scientific World Journal
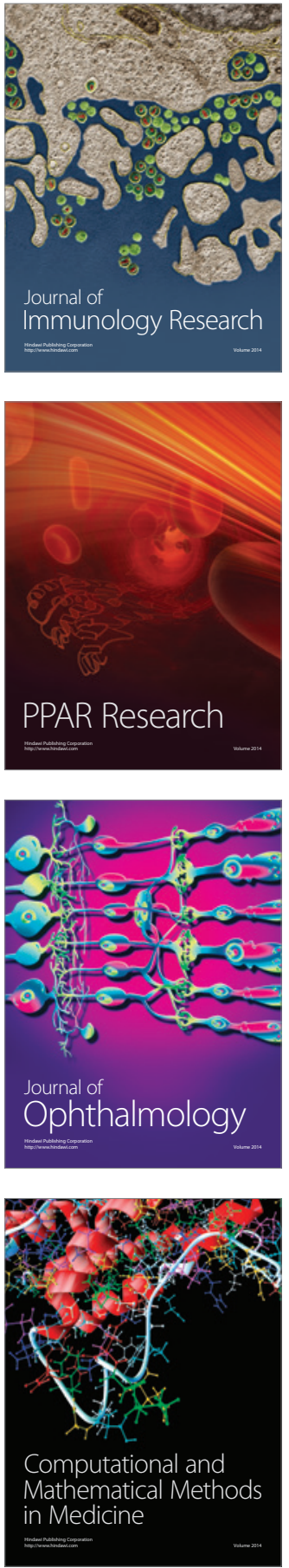

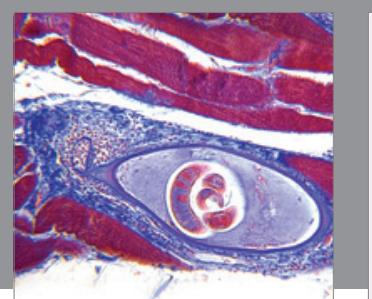

Gastroenterology Research and Practice

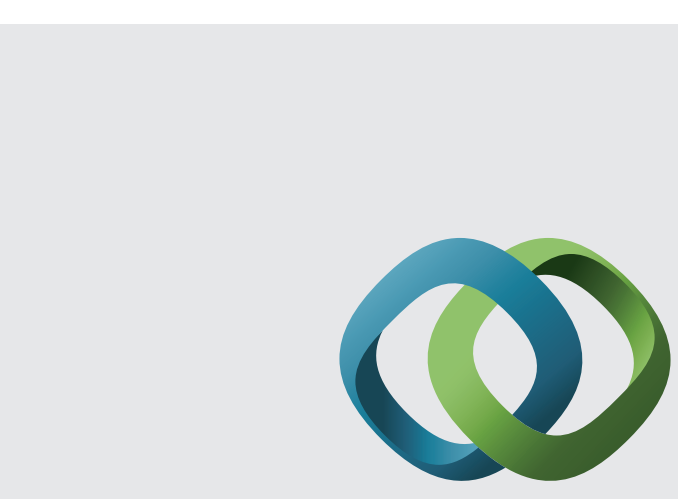

\section{Hindawi}

Submit your manuscripts at

http://www.hindawi.com
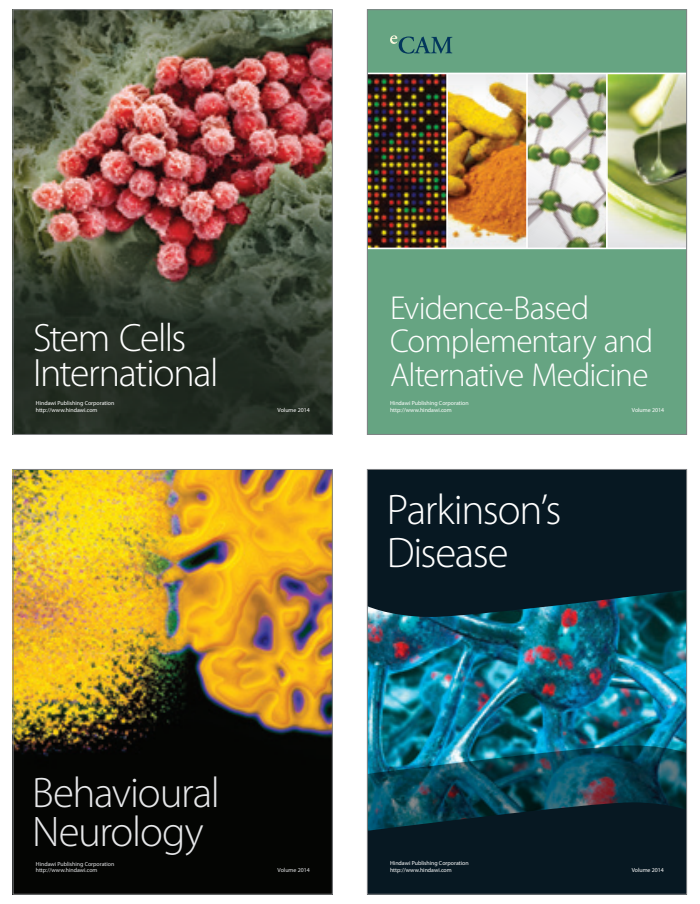
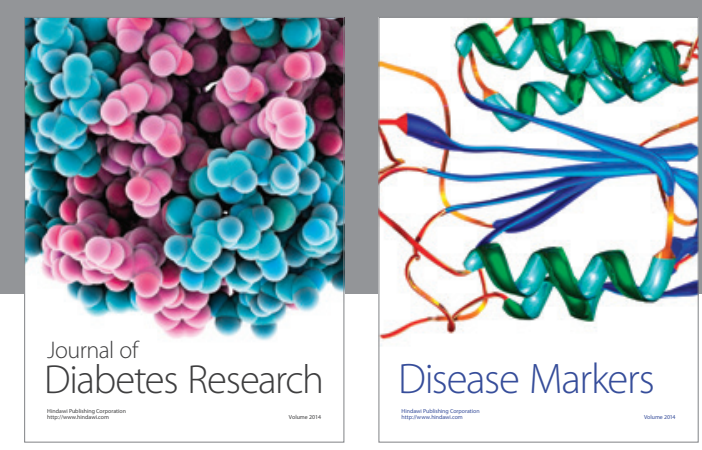

Disease Markers
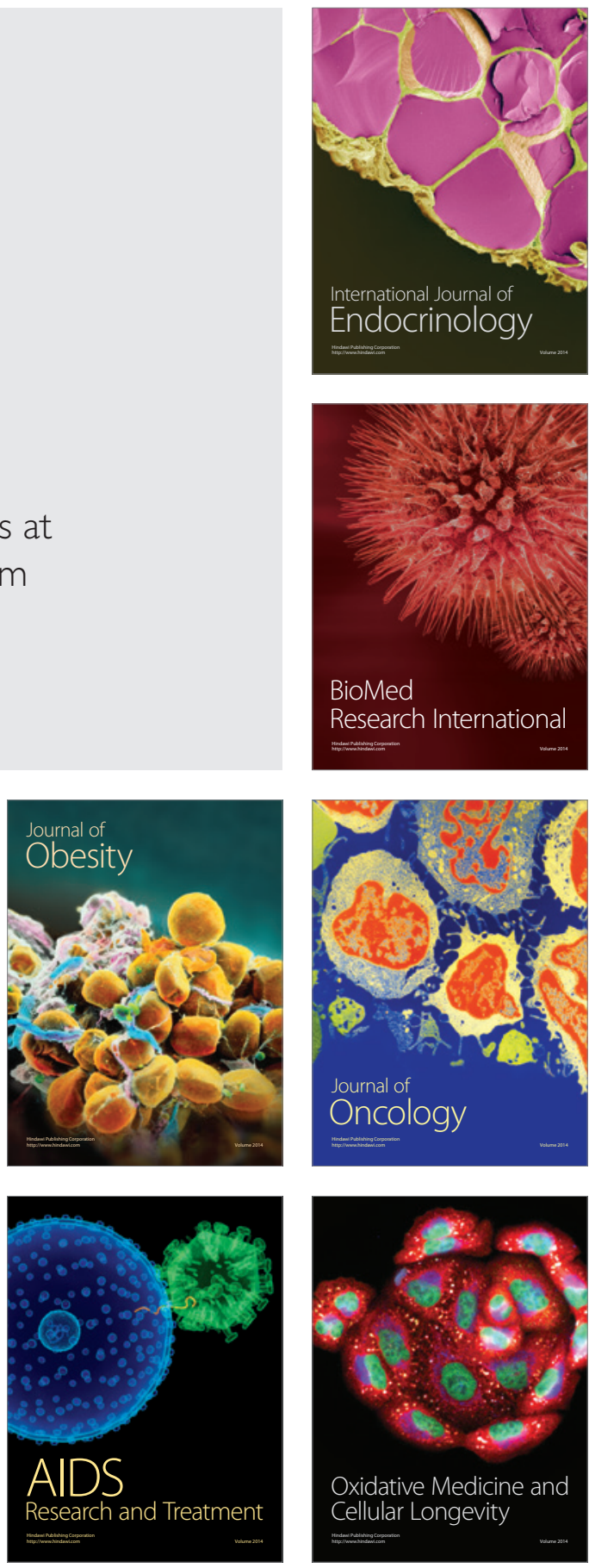